\title{
A scientific review of colorful textiles
}

\author{
Suna Nicolai ${ }^{1}$ (D) Tewes Tralau $^{2} \cdot$ Andreas Luch $^{1} \cdot$ Ralph Pirow $^{1}$
}

Received: 6 July 2020 / Revised: 5 October 2020 / Accepted: 8 October 2020 / Published online: 9 November 2020

(C) The Author(s) 2020

\begin{abstract}
Textiles, especially apparel, play an essential role in our daily life. Given that nearly everybody is in contact with clothes and other textiles $24 \mathrm{~h}$ a day, they have to be safe. Today's manufacturing processes depend on the use of many different chemicals, including dyes. An ideal dye would stay within the fabric during use. However, most textile dyes are prone to leaching and wear-off. Ideally, the industry is trying to keep the respective release of dyestuffs as low as possible. Concomitantly, toxicological risk assessment has to evaluate whether the released amounts are safe based on the substance-inherent characteristics and expected levels of exposure. So far, assessments of the latter are mostly based on what little data is available. Although the use of worst-case scenarios makes systematic overestimation likely and thus warrants a sufficiently high level of consumer protection, existing data gaps should be filled in order to end this unsatisfactory situation. Hence, in a first step this paper compiles and analyzes available data on the migration of dyes from textile materials, dermal dye uptake, and possible reductive cleavage of azo dyes by the skin microbiome as well as the dermal uptake of the resulting cleavage products.
\end{abstract}

Keywords Textiles $\cdot$ Clothing $\cdot$ Exposure $\cdot$ Dyes $\cdot$ Azo dyes $\cdot$ Aromatic amines

\section{Introduction}

Textile manufacturing requires a plethora of different chemicals: Apart from colorants, various textile auxiliaries are needed, e.g. levelling agents to achieve a uniform dyeing or finishing agents to achieve crease-resistance or water-repellency. Colorants can be classified according to their chemistry. Commonly used classes are e.g. azo, anthraquinone and metal-complex compounds. Depending on their solubility colorants can be divided into pigments, which are insoluble in the dyeing medium, and dyes which dissolve during application (IARC 2010). Finally, colorants can be classified by the dyeing process as such (Bechthold and Pham 2019).

Electronic supplementary material The online version of this article (https://doi.org/10.1007/s00003-020-01301-1) contains supplementary material, which is available to authorized users.

Suna Nicolai

Suna.Nicolai@bfr.bund.de

1 Department of Chemical and Product Safety, German Federal Institute for Risk Assessment (BfR), Max-Dohrn-Straße 8-10, 10589 Berlin, Germany

2 Department of Pesticide Safety, German Federal Institute for Risk Assessment (BfR), Max-Dohrn-Straße 8-10, 10589 Berlin, Germany
Acid (anionic) and basic (cationic) dyes form ionic bonds with textile fibers, while disperse dyes are hydrophobic compounds which are directly dissolved in the hydrophobic fiber matrix. Examples for the latter include polyester or cellulose acetate. While reactive dyes bind directly to the fiber via covalent bonds, direct dyes migrate into the fiber, where they remain enclosed in cavities. Vat and sulphur dyes are oxidized to water-insoluble derivates during the dyeing process and as such remain associated with the fiber.

Generally, among dyes in particular azo dyes feature high color and a wide structural diversity and are hence used in a variety of different dyeing processes. In addition, they are cheap to make and easy to produce. Therefore, azo dyes account for roughly half of the approximately 4000 dyes listed in the Color Index (BfR 2012) and for over 50\% of the world's annual production (Carliell-Marquet et al. 1995). Azo dyes are aromatic compounds that are characterized by at least one azo group $(-\mathrm{N}=\mathrm{N}-)$ which usually connects two aromatic rings. The azo double bond between the two nitrogen atoms can be cleaved by reducing agents such as sodium dithionite or enzymatically by for example azo reductases (Stolz 2001). In both cases the result is the release of primary aromatic amines (pAAs). Among these, some are known mutagens and/or carcinogens (Chung 2015; Levine 1991). Certain disperse azo dyes are skin sensitizers, and are 
currently a matter of discussion whether it is the dyes themselves or their metabolites which act as ultimate sensitizing species (Malinauskiene et al. 2012).

In 1994, Germany already restricted the use of azo dyes for certain commodities if the dye can be cleaved reductively into one of 20 carcinogenic pAAs. Later on, further European countries implemented a similar restriction (OECD 2005). This was followed by a European-wide restriction in 2003, implemented through Directive 2002/61/EC which amended the Directive 76/769/EEC relating to restrictions on the marketing and use of certain dangerous substances and preparations. This restriction banned azo dyes which, following reductive cleavage, may release one or more of 22 listed pAAs (including the 20 pAAs already banned nationally), for the use in textile and leather products that may come into direct and prolonged contact with the human skin or oral cavity. For the Directive to be effective, the amounts of released pAAs had to exceed $30 \mathrm{ppm}$ (i.e., $30 \mu \mathrm{g}$ per $\mathrm{g}$ fabric). The Directive was then subsequently replaced by the REACH Regulation (EC) No 1907/2006 in 2009. Also in 2009, Friedlipartner (Friedlipartner 2009) released an inventory of textile dyes that contained, amongst others, information on about 900 azo dyes from which approximately half fall under the above-mentioned restriction. The other azo dyes may break down to form pAAs that have not been in the regulatory focus so far. Brüschweiler et al. (2014), and Brüschweiler and Merlot (2017) recently showed that some of these pAAs emerge as "positives" in the so-called Ames assay, which represents a bacterial mutagenicity assay. The inventory from 2009 demonstrates the necessity of further hazard characterization of the non-regulated azo dyes and their corresponding pAAs, although it is no longer up to date. This is because a relevant number of additional REACH-registered textile azo dyes are available nowadays, whereas about two-thirds of the dyes on the list are only pre-registered under REACH and are therefore no longer allowed to be used in the EU, but they might be present in imported textiles.

Just as important as the hazard characterization is the estimation of the exposure of consumers towards chemicals in textiles. The internal exposure $D_{\text {int }}(\mu \mathrm{g} / \mathrm{kg} \mathrm{BW} /$ day) is calculated by the following equation

$D_{\text {int }}=\frac{A_{\text {skin }} \times m_{\text {prod }} \times c_{\text {subst }} \times f_{\text {use }} \times F_{\text {migr }} \times F_{\text {pen }}}{B W}$,

where $F_{\text {migr }}(\mu \mathrm{g} / \mu \mathrm{g})$ is the proportion of substance that is released during a wearing event and $F_{\text {pen }}(\mu \mathrm{g} / \mu \mathrm{g})$ is the proportion that subsequently penetrates the skin. Additionally, the exposed skin area $A_{\text {skin }}\left(\mathrm{cm}^{2}\right)$, the area density of the textile $m_{\text {prod }}\left(\mathrm{g} / \mathrm{cm}^{2}\right)$, the amount of chemical in the textile $c_{\text {subst }}(\mu \mathrm{g} / \mathrm{g})$, the wearing frequency $f_{\text {use }}(1 /$ day $)$, and the body weight $B W(\mathrm{~kg})$ are required. Variants of this calculation have been described in LGC (1998), Krätke and Platzek (2004), and ECHA (2016). However, in the case of azo dyes, reductive dye cleavage by skin bacteria needs to be considered additionally, together with possible dermal absorption of potential cleavage products. Yet, to our knowledge none of the available exposure models include these processes so far. In case of small children (toddlers) the oral uptake of textile chemicals through mouthing of textile parts could be an additional route of exposure which, however, shall not be considered here. The aim of the present paper is to review the existing data for the key steps of the pathway by which consumers become exposed to dyestuff from textiles, with a focus on azo dyes. As such this review therefore covers dye migration, reductive azo cleavage, and the dermal absorption of dyes as well as pAAs.

\section{Materials and methods}

The starting point for this review was a study cited by Krätke and Platzek (2004) to derive default values for the migration and dermal penetration of textile dyes and auxiliaries. Newer studies were included under the precondition that they added new information. Furthermore, the reductive cleavage of azo dyes and the dermal absorption of the cleavage products are addressed as well. Molecular masses (MW) and octanol-water partition coefficients ( $\log \mathrm{P}$ or XLogP3 (predicted $\log \mathrm{P}$ ) values) for the dyes were obtained from PubChem (for one dye from worldvariety.com). In the case of isotope-labeled compounds, the MW of the non-labeled dyes are given. Graphics were generated from original data using the statistical programming environment $\mathrm{R}^{1}$ with the $\mathrm{R}$ package ggplot $2 .^{2}$

\section{Migration of dyes from textiles}

Information on dye migration from textiles to skin is crucial for exposure assessment. One of the first studies addressing this topic was conducted in 1983 by the Ecological and Toxicological Association of Dyes and Organic Pigments Manufacturers (ETAD). They examined dye release of various dyes (substance identity not specified) into artificial sweat from single-dyed fabrics comprising polyester, cotton, cotton-polyester blend, acrylic, wool, wool-polyamide blend, polyamide 6 (PA 6, perlon) and 6,6 (PA 66, nylon) with fabric weights per unit area (WoFs) of $32-450 \mathrm{~g} / \mathrm{m}^{2}$. Dye specimens tested belonged to the categories of vat, reactive,

\footnotetext{
${ }_{1}$ https://www.r-project.org/ Accessed 6 October 2020.

2 https://cran.r-project.org/web/packages/ggplot2 Accessed 6 October 2020.
} 


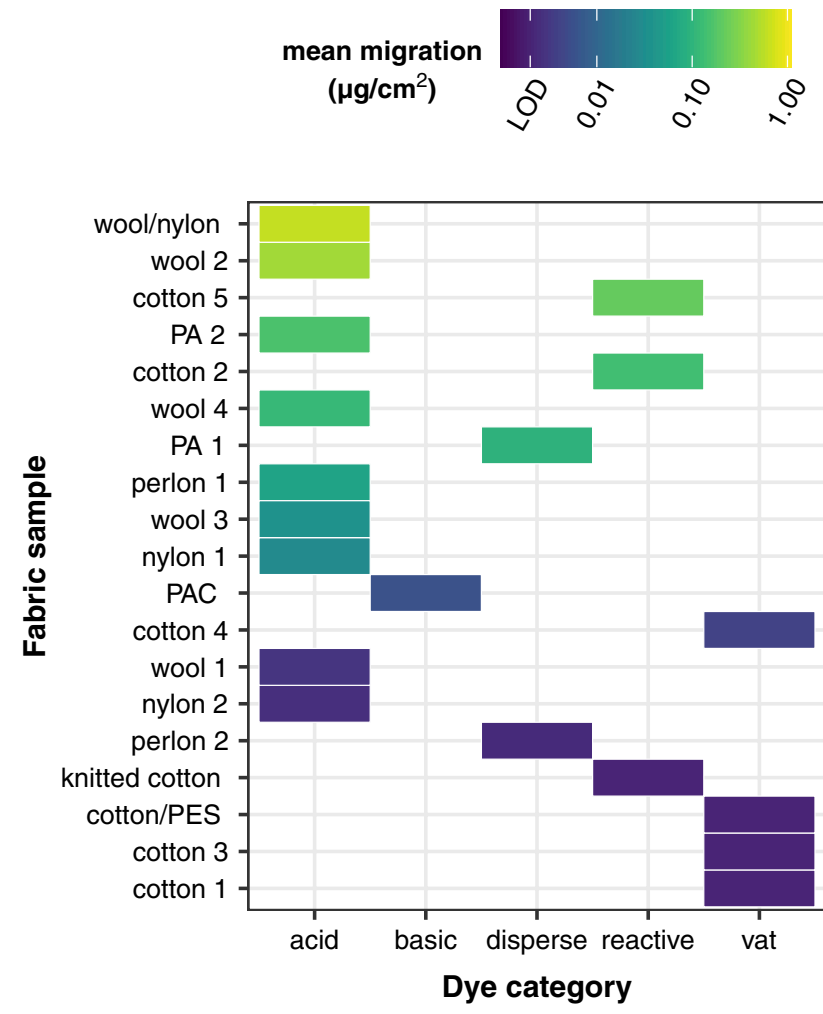

Fig. 1 Dye release into artificial sweat from single dyed fabrics. The tested dye-fabric combinations are indicated by colored rectangles on the grid. Dye release per unit area of fabric is coded by the color. The migration was measured using procedure I and alkaline sweat simulant (see text for details). The limit of detection (LOD) was $0.002 \mu \mathrm{g} /$ $\mathrm{cm}^{2}$. Numbers in sample names on the $y$-axis distinguish samples of same fabric type. $P A$ polyamide, $P A C$ polyacrylic, $P E S$ polyester. Data from ETAD (1983) (color figure online)

disperse, basic, and acid dyes. Depending on the dye-fabric combination, the amount of dye per unit area of fabric (dye load) was $9-510 \mu \mathrm{g} / \mathrm{cm}^{2}$.

ETAD used acidic (pH 5.5) and alkaline (pH 8.0) sweat simulants and two different migration procedures. In procedure I, the fabric sample was soaked with artificial sweat, sandwiched between two glass plates, and incubated at $37^{\circ} \mathrm{C}$ for $4 \mathrm{~h}$. The released dye was then extracted from the washing solution of the fabric and the glass plates. In procedure II, the fabric sample was shaken in a flask filled with sweat simulant at $37{ }^{\circ} \mathrm{C}$ for $4 \mathrm{~h}$ and squeezed prior to the spectrophotometric analysis of the simulant. In a ring trial with 14 participating laboratories, each dye-fabric combination was tested in several (mostly three) laboratories except for four polyester samples dyed with disperse dyes, which were excluded from the main analysis because no migration was observed in a pre-test. In total, 192 migration values were determined, $38 \%$ of which were below the limit of detection (LOD) of $0.002 \mu \mathrm{g} / \mathrm{cm}^{2}$. In terms of inter-laboratory reproducibility, for more than half of the triplicate determinations

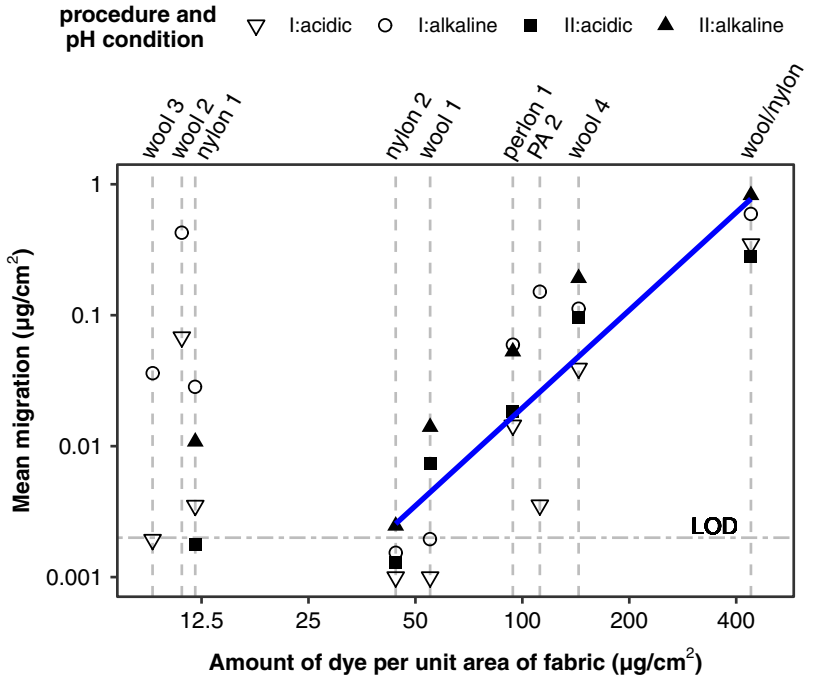

Fig. 2 Migration of acid dyes in relation to the amount of dye per unit area of fabric (dye load) for nine different samples. Data are shown on a double logarithmic scale. Two different extraction procedures (I and II) and two different perspiration simulants (acidic, alkaline) were used as indicated by the legend (see text for details). The limit of detection (LOD) of $0.002 \mu \mathrm{g} / \mathrm{cm}^{2}$ is indicated by the horizontal dotdashed line. The blue line was obtained by linear regression analysis using the data of the six samples with higher dye loads. The identity of the fabric samples is indicated on the top. $P A$ polyamide. Data from ETAD (1983)

with quantifiable releases, the coefficient of variation was less than $30 \%$. The mean dye release ranged from 0 to $0.83 \mu \mathrm{g} / \mathrm{cm}^{2}$ in absolute terms (Fig. 1) and 0 to $1.54 \%$ (w/w) in relative terms for samples with multiple measurements.

The data for nine acid-dyed fabrics were further analyzed for a possible correlation between the magnitude of dye release and dye load (Fig. 2). For six samples, there was a clear increase of dye release with an increasing dye load. Also, alkaline sweat simulant caused higher dye releases compared to acidic simulant while there was no obvious difference between the two extraction procedures.

In a subsequent study, ETAD (1997) examined the dye release from a PA 66 fabric (WoF: $260 \mathrm{~g} / \mathrm{m}^{2}$ ) over a simulated lifetime of use involving a number of washing and wearing cycles. The anthraquinone dye Disperse Blue 3 (DB3; $296 \mathrm{~g} / \mathrm{mol}$ ), the mono-azo dye Disperse Yellow (DY) 3 (269 g/mol), and the di-azo dye Acid Red 114 (AR114; $831 \mathrm{~g} / \mathrm{mol}$ ) were selected based on the expectation that they would show at least minimal migration. The experiments were conducted using two depths of color (a measure of the intensity of the color impression). In order to reflect standard conditions, measurements were performed using standard depth (SD) and a pronounced deeper shade for increased analytical accuracy. Standard depths were set up as $1 / 1 \mathrm{SD}$ and $1 / 6 \mathrm{SD}$, denoting fabric dying at one-sixth or full standard reference for color fastness testing, respectively 
Table 1 Dyestuff migration from single dyed fabric made of polyamide 6,6 (PA 66)

\begin{tabular}{|c|c|c|c|c|c|c|c|c|c|}
\hline \multirow[t]{2}{*}{ Dye } & \multirow[t]{2}{*}{ Depth of color } & \multicolumn{2}{|c|}{ Dye load } & \multicolumn{2}{|c|}{$\begin{array}{l}\text { Perspiration fast- } \\
\text { ness }\end{array}$} & \multicolumn{2}{|c|}{$\begin{array}{l}\text { Maximum dye } \\
\text { release }\left(\mu \mathrm{g} / \mathrm{cm}^{2}\right)\end{array}$} & \multicolumn{2}{|c|}{$\begin{array}{l}\text { Maximum dye } \\
\text { release }(\%)\end{array}$} \\
\hline & & $\mu \mathrm{g} / \mathrm{cm}^{2}$ & $\%(\mathrm{w} / \mathrm{w})$ & Acidic & Alkaline & Acidic & Alkaline & Acidic & Alkaline \\
\hline DY3 & $1 / 6 \mathrm{SD}$ & 12.6 & 0.05 & $4-5$ & $4-5$ & 0.017 & 0.017 & 0.13 & 0.13 \\
\hline DB3 & $1 / 6 \mathrm{SD}$ & 10.7 & 0.04 & 4 & 4 & 0.019 & 0.049 & 0.18 & 0.46 \\
\hline AR114 & 1/1 SD & 175.5 & 0.67 & $4-5$ & $4-5$ & 0.023 & 0.023 & 0.01 & 0.01 \\
\hline DY3 & $6 \times 1 / 6 \mathrm{SD}$ & 75.9 & 0.29 & 3 & 3 & 0.126 & 0.135 & 0.17 & 0.18 \\
\hline DB3 & $6 \times 1 / 6 \mathrm{SD}$ & 64.1 & 0.24 & 2 & $2-3$ & 0.166 & 0.286 & 0.26 & 0.45 \\
\hline AR114 & $2 \times 1 / 1 \mathrm{SD}$ & 351 & 1.35 & $4-5$ & $4-5$ & 0.023 & 0.023 & 0.01 & 0.01 \\
\hline
\end{tabular}

The fabric $\left(260 \mathrm{~g} / \mathrm{m}^{2}\right)$ was dyed with Disperse Yellow 3 (DY3), Disperse Blue 3 (DB3), or Acid Red 114 (AR114) at two different color depths, expressed in terms of standard depth (SD). Dye load and color fastness to perspiration (acidic: $\mathrm{pH} 5.5$, alkaline: $\mathrm{pH}$ 8.0) are given. Dye release into acidic and alkaline sweat solution was measured over a simulated lifetime of use (see text for details); the maximum dye release is given. Data from ETAD (1997)
(Table 1) (Hawkyard and Kelly 2000). In contrast, the pronounced deeper shades were dyed at twice and sextuple the standard depths (Table 1). The dye load was in the range of $10.7-351 \mu \mathrm{g} / \mathrm{cm}^{2}$.

The color fastness to perspiration (measured according to ISO 105-E04 (1989)) was close to the best score of five for samples dyed at color depths of practical relevance (1/6 SD, 1/1 SD) (Table 1). Among the overdyed samples, those with DY3 and DB3 got poorer grades of two to three. To measure dye release during a simulated wearing event, tissue samples were incubated in artificial sweat solution (liquor ratio of 1:20; i.e. $100 \mathrm{~g}$ fabric in $2 \mathrm{~L}$ solution) at $40{ }^{\circ} \mathrm{C}$ for $1 \mathrm{~h}$. The released dye was extracted from the sweat simulant and quantified by HPLC (LOD: 0.003, 0.004 and $0.009 \mu \mathrm{g} / \mathrm{cm}^{2}$ for DY3, DB3 and AR114, respectively). The textile samples were then subjected to 28 washing cycles to simulate a lifetime of use. Dye release was measured after the 1st, 2nd, $3 \mathrm{rd}, 4$ th, 16th and 28th washing cycle.

The maximum dye releases were $0.023,0.135$ and $0.286 \mu \mathrm{g} / \mathrm{cm}^{2}$ for AR114, DY3 and DB3, respectively (Fig. 3, Table 1); 0.01, 0.18 and $0.45 \%$ (w/w) of the dye load were released, respectively. While the release of AR114 was close to the LOD, the two other dyes showed quantifiable releases, the magnitude of which depended on the number of washing cycles and the depth of color. At the lower color depth $(1 \times 1 / 6 \mathrm{SD})$, both DB3 (only at $\mathrm{pH} 5.5$ ) and DY3 were released only in small amounts being close to the LOD. The other samples, dyed with DB3 $(1 \times 1 / 6 \mathrm{SD}$, pH 8.0 and $6 \times 1 / 6 \mathrm{SD})$ and DY3 $(6 \times 1 / 6 \mathrm{SD})$, showed exponentially decreasing dye release with increasing number of washing cycles. Notably this was sometimes preceded by an initial increase, though. Regarding DB3 at the higher depth of color, alkaline sweat simulant caused a higher migration than the acidic one.

Further studies from the German Institute for woolrelated research ("Deutsches Wollforschungsinstitut") came to similar results as those described above (Heine et al. 1996,
2000). Other studies confirmed that the dye release is low for fabrics that are dyed with state-of-the-art technology and which show a good color fastness. The Ciba Spezialitätenchemie AG (2000) analyzed the migration of three disperse dyes from a polyester-cotton blend (WoF: $210 \mathrm{~g} / \mathrm{m}^{2}$ ) and polyester microfiber fabric (WoF: $65 \mathrm{~g} / \mathrm{m}^{2}$ ) with a color fastness of 3-5. The maximum release was $0.07 \mu \mathrm{g} / \mathrm{cm}^{2}$, corresponding to $0.053 \%$ of the dye load. This low value contrasts with the high release from fabrics of poor color fastness. For such poor-quality products, Platzek and Lang (2002) measured a maximum migration of 3.0 and $11.9 \mu \mathrm{g} /$ $\mathrm{cm}^{2}$, respectively, for a 0.5 and $2 \%$ dyeing with Disperse Orange (DO) 3 on a polyamide fabric (WoF: $111 \mathrm{~g} / \mathrm{m}^{2}$ ), corresponding to $5.4 \%$ of the respective dye loads.

During the public consultation of the proposed REACH Annex XVII restriction of skin sensitizing substances in textile, leather, hide and fur articles (ECHA 2019), new data on the migration of five disperse dyes from polyester fabrics have been submitted (Kahlberg Consulting 2019). As seen before for disperse dyes on polyester, the migration was very low. Only the positive control Disperse Red 1 ( $2 \%$ dyeing) showed a migration of $0.12 \%$ of the dye load when using a 50:50 mixture of water and $n$-octanol as elution agent.

In summary, dye release from textiles is influenced by many parameters such as fabric type and weight, MW and $\log \mathrm{P}$ of the dye, and the $\mathrm{pH}$ of the sweat simulant. Washing and wearing of a textile reduces the dye release over time. Bad color fastness due to the use of non-state-of-the-art technology and over-dyeing, which can reduce the perspiration fastness, leads to higher dye releases. In contrast, fabrics manufactured by state-of-the-art technology and dyed at levels not exceeding the "standard" color depth were found to show maximum releases of $0.5-1 \%$ of the dye load. Considering the large number of variables that can influence the extractability of dyestuffs, migration values cannot be transferred from one dye-fabric system to another, and the 


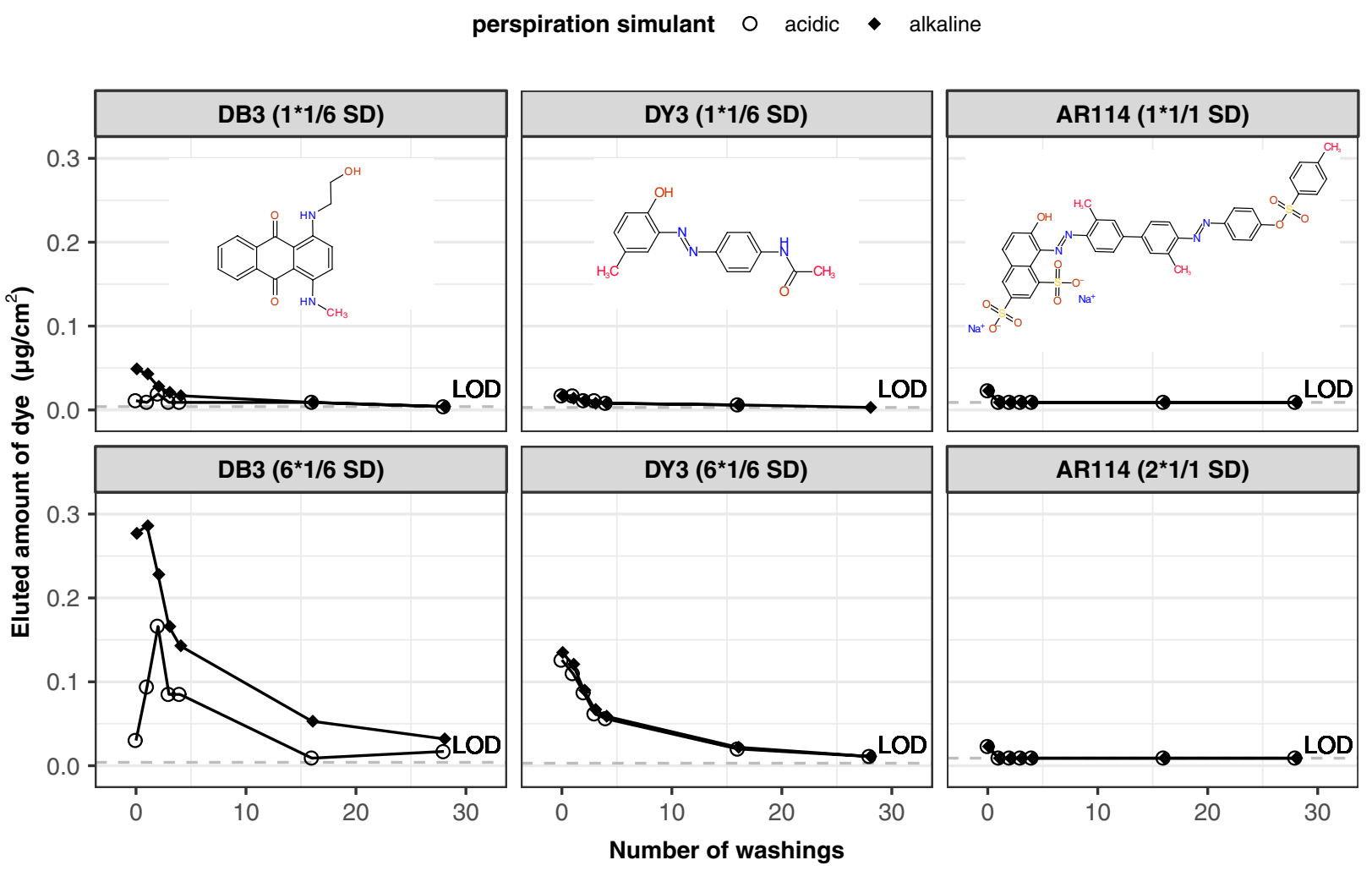

Fig. 3 Elution of three dyes from textile fabric in relation to the number of washing cycles. The textile fabric was dyed with Disperse Blue 3 (DB3), Disperse Yellow 3 (DY3), and Acid Red 114 (AR114) using two different color depths (given in brackets). Dye release was

available data described above can only be regarded as guidance values as to the order of magnitude of dye releases.

\section{Percutaneous absorption of textile dyes}

Percutaneous absorption is the next important issue in the assessment of internal exposure. Molecules that effectively penetrate the skin and transition through the different skin layers can then be taken up into the blood flow and become systemically available. In in vitro systems such as Franz diffusion cells, this step is mimicked by its appearance in the receptor fluid (SCCS 2010).

Aldrich et al. (1986) studied the excretion of radioactivity in Fischer-344 rats and New Zealand rabbits after topically applying the ${ }^{14} \mathrm{C}$-labeled tri-azo dye Direct Black 38 (DB38; $782 \mathrm{~g} / \mathrm{mol}$ ) or the tetra-azo dye Direct Black 19 (DB 19; $840 \mathrm{~g} / \mathrm{mol}$ ). Dosing parameters were derived from the reported specific activities: The dyes were dissolved in alkaline sodium carbonate buffer at concentrations of $3330 \mu \mathrm{g} / \mathrm{mL}$ (DB38) and 17,000 $\mu \mathrm{g} / \mathrm{mL}$ (DB19). 27, 3 or $8 \mu \mathrm{L} / \mathrm{cm}^{2}$ dye solution were applied onto shaved dorsal skin resulting in surface doses of $89 \mu \mathrm{g} / \mathrm{cm}^{2}$ DB38 and measured using two different perspiration simulants (acidic, alkaline). Horizontal dashed lines indicate the dye-specific limit of detection (LOD) of 0.004 (DB3), 0.003 (DY3), and $0.009 \mu \mathrm{g} / \mathrm{cm}^{2}$ (AR114), respectively. Data from ETAD (1997)

$44 \mu \mathrm{g} / \mathrm{cm}^{2}$ (rat) or $131 \mu \mathrm{g} / \mathrm{cm}^{2}$ (rabbit) DB19. Applied dye solutions were dried using a hair dryer and application sites were protected with a barrier assembly without occlusion. The dye remained on the skin over a six-day period, during which urine and fecal samples were collected on a daily basis.

Cumulative excretion of radioactivity (expressed as dye equivalents) increased almost linearly in the urine as well as in feces, at least during the first days. That is with the exception of DB19 in rabbits for which fecal excretion was only observed on day 1 (Fig. 4). The linearity of the cumulative excretion profiles implies a steady-state flux of dye equivalents through the skin and the animals. The total excretion of DB38 via both routes corresponds to percutaneous fluxes of 0.0008 (rats) and $0.0304 \mu \mathrm{g} / \mathrm{cm}^{2} / \mathrm{h}$ (rabbits), respectively. For DB19, considerably lower values of 0.0001 (rats) and $0.0004 \mu \mathrm{g} / \mathrm{cm}^{2} / \mathrm{h}$ (rabbits) were obtained. The authors interpreted the excreted radioactivity as indication that the dyes' azo bonds were cleaved by the skin microbiome (and possibly also by skin enzymes), resulting in the release of ${ }^{14} \mathrm{C}$-labeled cleavage products. Also, the higher excretion in DB38-treated rabbits compared to rats could result from differences in the skin microflora and skin permeability. 


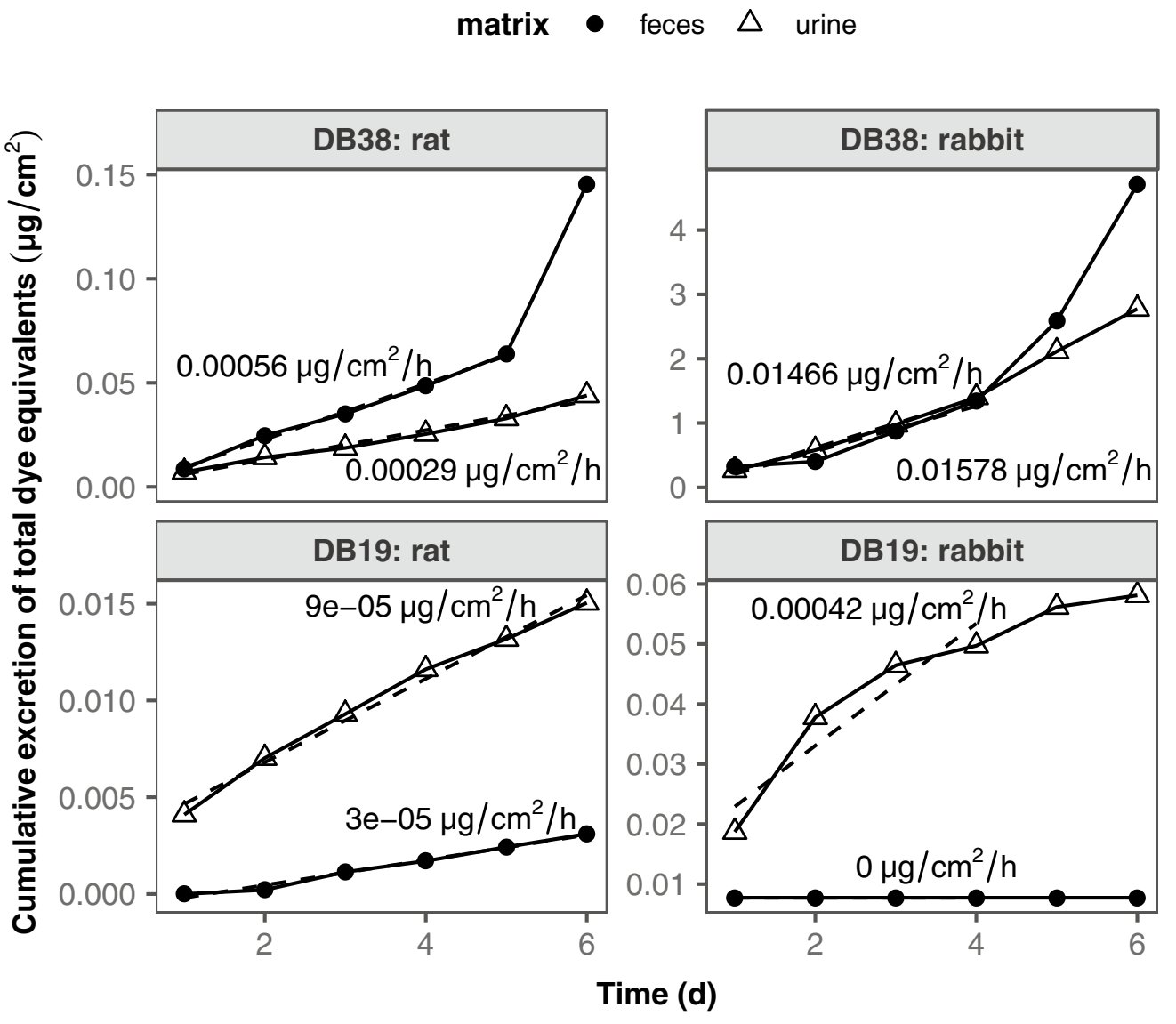

Fig. 4 Cumulative excretion of total dye equivalents in feces and urine of Fischer-344 rats and New Zealand rabbits after dermal application of $89 \mu \mathrm{g} / \mathrm{cm}^{2}$ Disperse Black 38 (DB38) or of $44 \mu \mathrm{g} / \mathrm{cm}^{2}$ (rat) and $131 \mu \mathrm{g} / \mathrm{cm}^{2}$ (rabbit) Disperse Black 19 (DB19). Regression lines

Collier et al. (1993) studied the in vitro percutaneous absorption of the mono-azo dyes Sudan I (SDI, $248 \mathrm{~g} /$ mol), Solvent Yellow 7 (SY7; $198 \mathrm{~g} / \mathrm{mol}$ ), and Acid Orange 12 (AO12; $350 \mathrm{~g} / \mathrm{mol})$ in viable skin $(200 \mu \mathrm{m}$ thick) from SENCAR mouse, hairless guinea pig (HGP), and man using flow-through diffusion cells. The dyes were ${ }^{14} \mathrm{C}$-labeled within their aniline moiety. $10 \mu \mathrm{L}$ dye solution (SDI and SY7 in acetone, AO12 in acetone-methanol) was topically applied to an area of $0.64 \mathrm{~cm}^{2}$ yielding in a surface dose of $5 \mu \mathrm{g} / \mathrm{cm}^{2}$. After $24 \mathrm{~h}$, the radioactivity was measured in the partially tape-stripped skin and in the receptor fluid and expressed as total dye equivalents (parent compound and metabolites).

$21.1 \%$ (SDI) and $13.7 \%$ (SY7) of the applied dose where recovered in human skin. Further 8.6 and $22.4 \%$ were found in the receptor fluid, resulting in a total absorption of $1.5 \mu \mathrm{g} /$ $\mathrm{cm}^{2}$ (29.7\% of the applied dose) for SDI and $1.8 \mu \mathrm{g} / \mathrm{cm}^{2}$ (36.1\%) for SY7. Animal skin showed a higher absorption: 32.8 and $52.7 \%$ (SDI) as well as 64.1 and $67.8 \%$ (SY7) were (dashed lines) indicate the time periods of constant excretion, and associated values indicate the excretion rates. Please note the different scales on the $y$-axis. Data from Aldrich et al. (1986)

absorbed by mouse and HGP skin, respectively. AO12, which only differs from SDI by a sulfonate group, did not penetrate in greater amounts. The study demonstrates that an internal exposure to dyes and their cleavage products can occur via the dermal route. Two of the three dyes were absorbed to a greater extent by skin from all species with much higher values for animal skin.

ETAD (1994) investigated the in vitro absorption of the mono-azo dyes Disperse Red (DR) 17 (344 g/mol), DY3 (269 g/mol), and Disperse Blue 165 (DB165; $405 \mathrm{~g} / \mathrm{mol}$ ) through human and pig epidermal skin in static diffusion cells. Additionally, the anthraquinone dye DR60 (331 g/ $\mathrm{mol})$ were tested, the quinoline dye DY64 (368 g/mol), and T2030/76 (unknown substance identity). All dyes were lipophilic with predicted $\log \mathrm{P}$ values ranging from 2.6 to 4.5 . Whole pig-ear and human skin were immersed in water at $60{ }^{\circ} \mathrm{C}$ for $40-50 \mathrm{~s}$; the epidermis became gently detached and stored deep-frozen. Dye suspensions $(1000 \mu \mathrm{g} / \mathrm{mL}$ in $0.5 \%$ Tween 80 in distilled water) were applied topically at a rate 


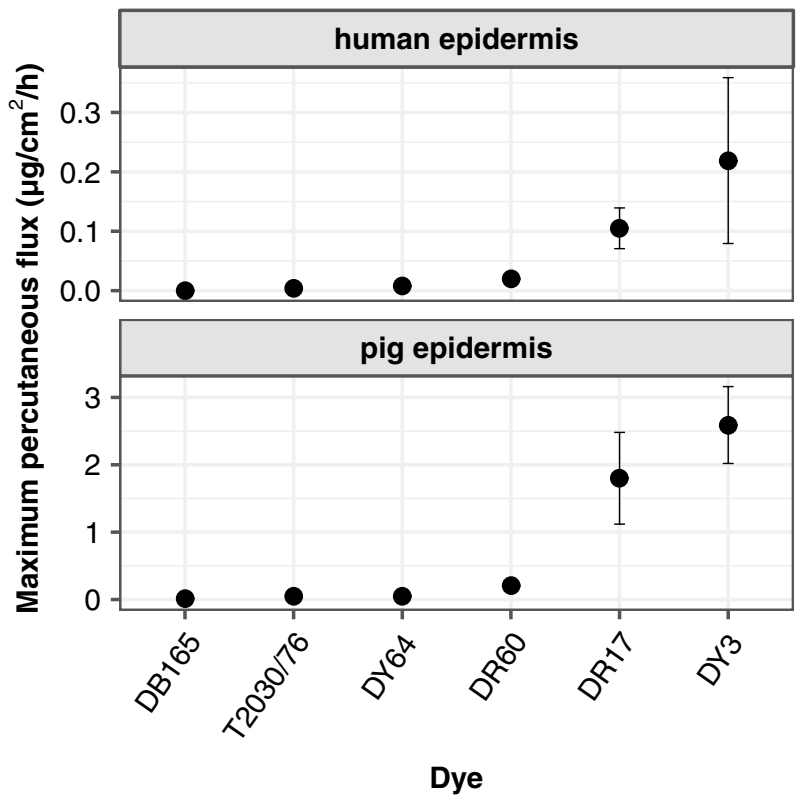

Fig. 5 Maximum in vitro percutaneous flux $\left(\mu \mathrm{g} / \mathrm{cm}^{2} / \mathrm{h}\right)$ of the disperse dyes Disperse Blue 165 (DB165), T2030/76, Disperse Yellow 64 (DY64), Disperse Red 60 (DR60), Disperse Red 17 (DR17) and Disperse Yellow 3 (DY3) through non-viable human and pig epidermis ( $\mathrm{n}=6$ each). $200 \mu \mathrm{g} / \mathrm{cm}^{2}$ dye in $0.5 \%$ Tween 80 solution were applied on the skin surface of diffusion cells with a rate of $200 \mu \mathrm{L} /$ $\mathrm{cm}^{2}$. The maximum percutaneous flux was determined from the steep linear part of the time profile for cumulative percutaneous absorption. Please note the different scales on the $y$-axis. Data from ETAD (1994) (color figure online)

of $200 \mu \mathrm{L} / \mathrm{cm}^{2}$, resulting in a surface dose of $200 \mu \mathrm{g} / \mathrm{cm}^{2}$. Donor chambers were occluded during the $55 \mathrm{~h}$-exposure, and samples of the receptor fluid (50\% ethanol in distilled water) were analyzed by HPLC. The maximum percutaneous flux $\left(\mu \mathrm{g} / \mathrm{cm}^{2} / \mathrm{h}\right)$ was determined from the steep linear part of the time profile for the cumulative percutaneous absorption.

The absorption through pig skin was 10-20 times higher than through human skin for all tested dyes (Fig. 5). Lag times varied between 4 and $10 \mathrm{~h}$; at the end of the experiments, $0-11.7 \mu \mathrm{g} / \mathrm{cm}^{2}$ and $0.6-90 \mu \mathrm{g} / \mathrm{cm}^{2}$ of the dye had penetrated human and pig skin, respectively. While DB165 exhibited the lowest absorption, DY3 showed the highest flux with 0.2 and $2.6 \mu \mathrm{g} / \mathrm{cm}^{2} / \mathrm{h}$ for human and pig skin, respectively. In comparison to Collier et al. (1993), the amount of dye found in the receptor fluid at the end of the experiments was much higher for some of the samples. This could be due to the higher surface dose $\left(200 \mu \mathrm{g} / \mathrm{cm}^{2}\right)$ and longer incubation time ( 55 vs. $24 \mathrm{~h}$ ). In addition, the ETAD study used epidermal skin (usually $<100 \mu \mathrm{m}$ thick) whereas Collier et al. used $200 \mu \mathrm{m}$ thick skin.

In a follow-up study, ETAD (1995) used human epidermal skin and the above methodology to investigate the absorption of DR60 and DY3 from saturated solutions in acidic sweat simulant (pH 5.5, DR60: $24.4 \mu \mathrm{g} / \mathrm{mL}$, DY3: $20.9 \mu \mathrm{g} / \mathrm{mL}$ ) as well as from five formulations. Sweatdye solutions were applied at a rate of $200 \mu \mathrm{L} / \mathrm{cm}^{2}$ under occlusive conditions. The resulting surface doses of 4.9 and $4.2 \mu \mathrm{g} / \mathrm{cm}^{2}$ led to maximum percutaneous fluxes of $0.020 \mu \mathrm{g} /$ $\mathrm{cm}^{2} / \mathrm{h}$ and $0.090 \mu \mathrm{g} / \mathrm{cm}^{2} / \mathrm{h}$ for DR60 and DY3, respectively. In comparison to the study from 1994, the maximum flux for DY3 was only 2.2 times lower, although the surface doses were $\sim 40$ times lower. This could be due to an overdose in the study from 1994 or because of the different solvents (sweat simulant vs. Tween 80 in water). The test formulations, which were applied under non-occlusive conditions at a rate of $10 \mu \mathrm{L} / \mathrm{cm}^{2}$, contained $2.5 \%$ of dye as well as $7.5 \%$ of one of five dispersing agents. The resulting surface dose of $\sim 250 \mu \mathrm{g} / \mathrm{cm}^{2}$ was comparable to that used in ETAD (1994) but the applied volume per skin surface area was 20 -fold lower. Depending on the dispersing agent, the maximum percutaneous flux ranged from non-quantifiable levels of $<0.001$ to $0.006 \mu \mathrm{g} / \mathrm{cm}^{2} / \mathrm{h}$ for DR60 and $0.012 \mu \mathrm{g} /$ $\mathrm{cm}^{2} / \mathrm{h}$ for DY3. The maximum fluxes were 3- to 18 -fold lower than the values determined for the corresponding dye suspensions in 1994.

Another study by ETAD (2001) used human and pig epidermal skin and measured the in vitro percutaneous absorption of the lipophilic mono-azo dyes DR82 $(439 \mathrm{~g} / \mathrm{mol})$ and DO30 (450 g/mol) from acidic sweat simulant (pH 5.5) and from "dried-on" depositions from acetone solutions under occlusive conditions. Human skin was taken post mortem from the abdominal region. Saturated dye solutions (unknown concentration) in sweat simulant were applied at a rate of $200 \mu \mathrm{L} / \mathrm{cm}^{2}$. The maximum percutaneous flux in human epidermis was non-quantifiable for DR82 and $0.004 \mu \mathrm{g} / \mathrm{cm}^{2} / \mathrm{h}$ for DO30. Pig epidermis showed higher values of $0.002 \mu \mathrm{g} / \mathrm{cm}^{2} / \mathrm{h}$ (DR82) and $0.022 \mu \mathrm{g} / \mathrm{cm}^{2} / \mathrm{h}$ (DO30). Acetone solutions of DR82 $(6 \mu \mathrm{g} / \mathrm{mL})$ or DO30 $(60 \mu \mathrm{g} / \mathrm{mL})$ were applied at a rate of $10 \mu \mathrm{L} / \mathrm{cm}^{2}$ and left unoccluded for the first $15 \mathrm{~min}$ to enable the evaporation of the acetone vehicle, resulting in surface doses of 0.06 and $0.60 \mu \mathrm{g} / \mathrm{cm}^{2}$, respectively. Ethanol or the surfactant Volpo N20 (in water or pure) were used as receptor fluid. The percutaneous flux was only quantifiable for pig skin with ethanol as receptor fluid, yielding values of $0.002 \mu \mathrm{g} / \mathrm{cm}^{2} / \mathrm{h}$ (DR82) to $0.007 \mu \mathrm{g} /$ $\mathrm{cm}^{2} / \mathrm{h}$ (DO30). For human skin even tenfold higher doses did not result in a measurable absorption.

Altogether the three ETAD studies clearly show that disperse dyes can penetrate the skin, with animal epidermal skin showing a higher absorption compared to human skin in vitro. Despite the interspecies difference, pig skin turned out to be a suitable model to predict the relative rates of disperse dye absorption. The extent of absorption is influenced by solvent type, volume rate, surface dose, occlusion conditions, type of receptor fluid, and the MW, $\log P$ and aqueous solubility of the dye. 
Meinke et al. (2009) used textile samples, dyed with the fluorescent, lipophilic non-azo dye DY184:1 (348 g/mol), to study the simultaneous migration and penetration into excised pig-ear skin and back skin of human volunteers. Penetration into stratum corneum (SC) was analyzed by using the tape-stripping procedure and fluorescence spectroscopy. The textile, a polyester/cotton fabric (65/35; WoF: $180 \mathrm{~g} /$ $\mathrm{m}^{2}$ ), was prewashed, dyed, dried and fixed. The dyed fabric was rinsed in a suboptimal manner to enable an increased dye migration (a worst-case scenario). Elution of the dyed fabric with sweat simulants (liquor ratio: 1:50) of different $\mathrm{pH}$ at $40{ }^{\circ} \mathrm{C}$ under shaking conditions showed migration rates of $17.8(\mathrm{pH} 5.5), 18.2(\mathrm{pH} 6.8)$, and $22.7 \mu \mathrm{g} / \mathrm{cm}^{2}$ $(\mathrm{pH} 8.0)$. These migration rates were manifold higher than the releases observed in textiles that had been dyed according to state-of-the-art procedures (see above).

Pig ear skin was obtained from freshly slaughtered domestic pigs. A piece of the dyed textile (area: $3 \times 6 \mathrm{~cm}^{2}$ ) was soaked with neutral sweat solution, applied onto the depilated porcine skin, and an occlusion patch covered the applied textile. Following the incubation at $32{ }^{\circ} \mathrm{C}$ for $3 \mathrm{~h}$, the upper SC layers were removed by 10 adhesive tape strips. The first five tapes and the tapes 6-10, respectively, were pooled, extracted, and analyzed. A mean dye amount of $0.031 \mu \mathrm{g} / \mathrm{cm}^{2}$ was recovered from the tape-stripped SC. About $85 \%$ of the dye was located in the first five tape strips. Increasing the incubation time to $6 \mathrm{~h}$ did not significantly change the amount of dye recovered from the SC.

A piece of the textile $\left(3 \times 6 \mathrm{~cm}^{2}\right)$ was put on the lower back of the volunteers and covered by an occlusive patch. One group of six volunteers wore the textile for $12 \mathrm{~h}$ without performing any extra sportive activity to present the normal way of wearing a clothing textile. A second group of 12 volunteers was running for $30 \mathrm{~min}$ to enhance sweat production. At the end of the exposure time, the textile sample was removed, and the exposed skin area was left to dry and tape-stripped 10 times. After wearing the textile in a normal way for $12 \mathrm{~h}, 0.027 \mu \mathrm{g} / \mathrm{cm}^{2}$ was recovered from the tapestripped SC, being comparable to that found in the in vitro setting using pig skin (see above). In the sports groups, after running for $30 \mathrm{~min}$, a two-fold higher amount of $0.055 \mu \mathrm{g} /$ $\mathrm{cm}^{2}$ was recovered. Because the exposed skin was left to dry and remaining dye on the skin surface was not removed, higher amounts in the sport experiment could result from a higher elution of dye from the fiber but not necessarily from a higher skin penetration. Furthermore, only the amount of dye in the upper SC layers was analyzed, so that it is likely that the total penetrated amount were higher, especially in the $12 \mathrm{~h}$ experiments.

The studies discussed above show that dermal exposure of consumers to (azo) dyes from textiles can indeed occur. Important factors are the dye characteristics (MW, water solubility, $\log \mathrm{P}$ ) and the experimental setup (applied dose, occlusion, duration, solvents). The amount of sweat has an influence on the levels of elution, so that the penetrated amounts will be higher for similar wearing times. Skin thickness and skin integrity are additional factors affecting dermal absorption. Analytical techniques - especially the resolution and sensitivity — are rapidly evolving. From today's perspective, older studies often no longer meet today's standards and requirements for absorption studies, and results are associated with a certain degree of uncertainty. For more generalized statements it is necessary to broaden the data base using standardized experimental setups and up-to-date analytical methods.

\section{Reductive cleavage of azo dyes}

Enzymes of liver, skin, gut, and skin microbiome (Collier et al. 1993; Feng et al. 2012; Platzek et al. 1999) as well as other organisms (Chengalroyen and Dabbs 2013) are able to reductively cleave azo dyes. While the gut hosts mostly anaerobic bacteria, the human skin has both aerobic and anaerobic areas. Most bacterial azo reductases characterized so far are from aerobic strains. While the reductive cleavage of azo dyes by bacteria in wastewater treatment is relatively well understood (Chengalroyen and Dabbs 2013; Saratale et al. 2011; Solís et al. 2012), much less is known about the azo reducing capacity of skin bacteria, especially under in situ and in vivo conditions.

Collier et al. (1993) analyzed the reductive cleavage of the mono-azo dyes SDI, SY7, and AO12 when measuring the in vitro percutaneous absorption in viable skin from mouse, HGP, and man using flow-through diffusion cells (see above). The ${ }^{14} \mathrm{C}$-labeled dyes were applied in a finite surface dose of $5 \mu \mathrm{g} / \mathrm{cm}^{2}$. After $24 \mathrm{~h}$, radioactivity was then measured in the receptor fluid following HPLC-separation as to distinguish the parent compounds from any aniline metabolites (e.g., acetanilide, 4-acetaminophenol). In the case of SDI and SY7, both of which carry only one hydroxy group as the only substituent and which are lipophilic (XLogP3: 4.1 and 3.7$), 29.5 \%$ and $26.5 \%$ of the dose in the receptor fluid underwent azo reduction in human skin. For mouse and HGP skin, up to $61 \%$ of the penetrated amount was cleaved. In contrast, $\mathrm{AO} 12$ which possesses a sulfonyl group in addition to the hydroxy group showed an extremely low percutaneous absorption for all three species. Consequently, any metabolites (if present) were below the limit of detection.

Platzek et al. (1999) showed that various skin bacteria strains as well as skin bacteria isolated from healthy volunteers, mainly isolates of the genera Staphylococcus (St.) and Micrococcus (M.), are capable of cleaving the sulfonated di-azo dye Direct Blue 14 (DB14; $960 \mathrm{~g} / \mathrm{mol}$ ). In a standard experiment, $3 \times 10^{11}$ cells from the late-stationary phase were cultivated in $20 \mathrm{~mL}$ sweat simulant ( $\mathrm{pH}$ 6.8) with 


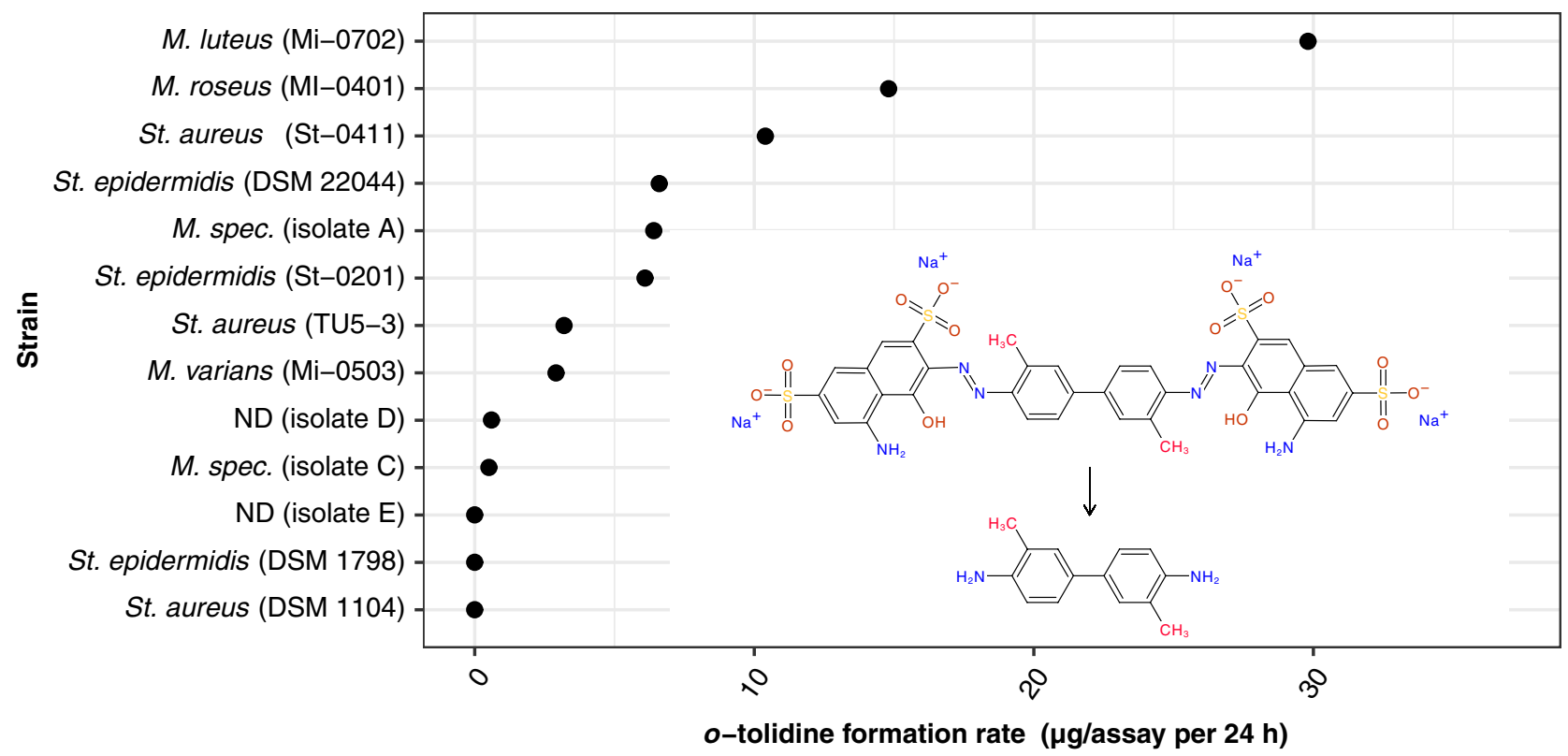

Fig. 6 Formation of $o$-tolidine as one of the cleavage products of Direct Blue 14 (DB14) by various skin bacteria in acidic perspiration simulant $\left(\mathrm{pH}\right.$ 6.8) after incubation at $28{ }^{\circ} \mathrm{C}$ for $24 \mathrm{~h}$. Each experiment used $3 \times 10^{11}$ cells from one skin bacteria strain or from one

$7 \mathrm{mg} \mathrm{DB} 14(364.28 \mu \mathrm{M})$ at $28^{\circ} \mathrm{C}$ for $24 \mathrm{~h}$. The formation of $o$-tolidine (OT), one of the expected cleavage products, was analyzed by HPLC and GC-MS to quantify the reduction. Some of the tested strains were able to cleave DB14, with strain M. luteus MI-0702 showing the highest OT formation rate of $30 \mu \mathrm{g}$ per assay, corresponding to a $3.8 \%$ reduction of the dye substrate (Fig. 6).

In a follow-up study, Balszuweit (2005) incubated five bacterial strains from human skin with 13 different azo dyes to analyze their metabolic capacity and to determine whether the availability of oxygen influences the extent of azo cleavage (Fig. 7). The substances comprised a mono-azo dye (Solvent red 1) and 12 di-azo dyes with MW of 278-993 g/ mol. Depending on the dye, there was either nearly no cleavage (two lipophilic dyes), a cleavage under anaerobic conditions only (four sulfonated dyes), or a cleavage under both aerobic and anaerobic conditions (three lipophilic and three sulfonated dyes). The higher cleavage rate occurred in the absence of oxygen, which was explained by the higher availability of the reducing coenzyme $\mathrm{NAD}(\mathrm{P}) \mathrm{H}$ for use by azo reductases.

Stingley et al. (2010) compared the reducing capacity of 26 different skin bacteria (mainly Staphylococcus) by using the carboxylated mono-azo dye Methyl Red (MR; $269 \mathrm{~g} /$ mol) and the sulfonated mono-azo dye Orange II (OrII; $350 \mathrm{~g} / \mathrm{mol}$ ) as substrates (Fig. 8). Each strain was incubated with $50 \mu \mathrm{M}$ MR and $100 \mu \mathrm{M}$ OrII, respectively, in skin bacteria isolate from healthy volunteers (ND if the strain was not known). The strain number from the supplier or the identification letter of the isolate are given in parenthesis. St. Staphylococcus, M. Micrococcus. Data from Platzek et al. (1999) (color figure online)

brain heart infusion medium at $37^{\circ} \mathrm{C}$ for $24 \mathrm{~h}$ (Kytococcus sedentarius at $26^{\circ} \mathrm{C}$ for $48 \mathrm{~h}$ ). The cleavage was followed by the decolorization of the cell suspensions. While MR was reduced completely by all strains except three, OrII was only reduced entirely by three strains within the $24 \mathrm{~h}$ incubation period (Fig. 8a). The remaining reaction mixes showed incomplete reductions between $0 \%$ to close to $100 \%$ (Fig. 8b). Differences in the turnover of MR and OrII could result from different initial concentrations (50 vs $100 \mu \mathrm{M}$ ) and the dye-specific reducing capacities of the bacterial strains.

Ito et al. (2018) collected bacteria from the fingertips of nine volunteers to investigate inter alia the azo-reducing capacity of the skin microbiome. Randomly picked cultures were transferred into $10 \mathrm{~mL}$ of $\mathrm{M} 9$ liquid medium, and the sulfonated di-azo dye Congo red was added in a final concentration of $20 \mathrm{mg} / \mathrm{L}(30.64 \mu \mathrm{M})$. After degassing of the medium to establish anaerobic conditions, the reaction vessels were slightly shaken at $37{ }^{\circ} \mathrm{C}$ for a maximum of three weeks (incomplete turnover), or until complete decolorization of the medium. As expected, it was possible to isolate azo-reducing bacteria from the skin microbiome. Six out of 45 colonies (13.3\%) were able to reduce Congo red at higher rates of $10-30 \mu \mathrm{g} / \mathrm{day}$, with three $M$. luteus isolates showing the highest reduction capacities.

Hence, selected skin bacteria were able to cleave various azo dyes, at least under cell culture conditions. The extent of 


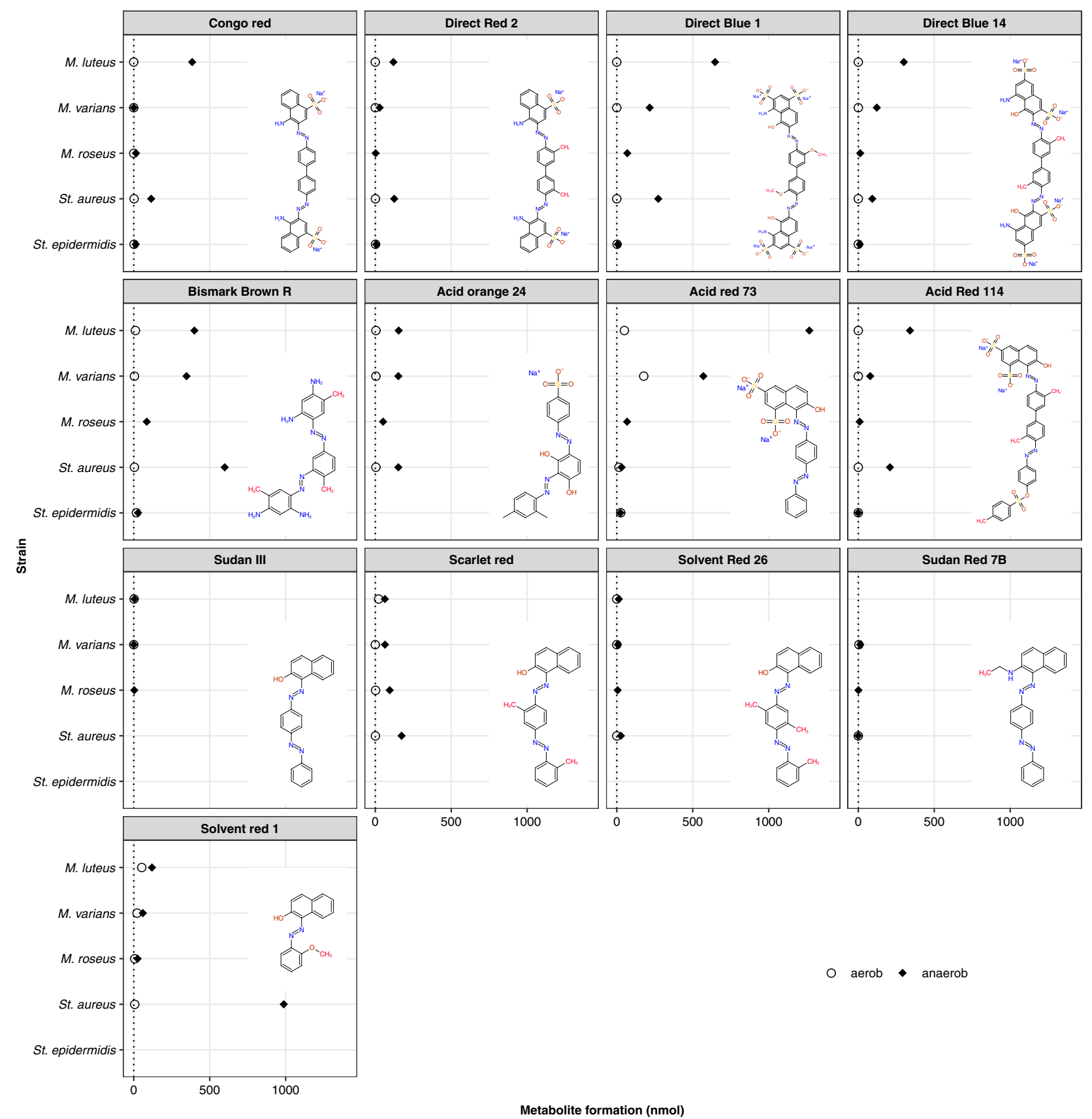

Fig. 7 Metabolite formation through reductive azo dye cleavage of 13 azo dyes by five bacterial strains in acidic perspiration simulant (pH 6.8) after incubation at $28{ }^{\circ} \mathrm{C}$ for $24 \mathrm{~h}$ under aerobic and anaerobic conditions. St. Staphylococcus, $M$. Micrococcus. Data from (Balszuweit 2005)

azo reduction ranged from partial to complete, depending on bacterial strain, dye concentration and properties, and oxygen availability. So far, it is unclear whether these findings apply as well to the physiological conditions on human skin in situ and/or in vivo. There is reason to assume that bacteria behave differently on the skin than in cell culture because of alternative sources of nutrition and interactions with other bacterial strains. Therefore, further studies are required that may involve the use of excised human skin or reconstructed human skin models in order to clarify whether the findings discussed above are transferable to the in vivo situation. 


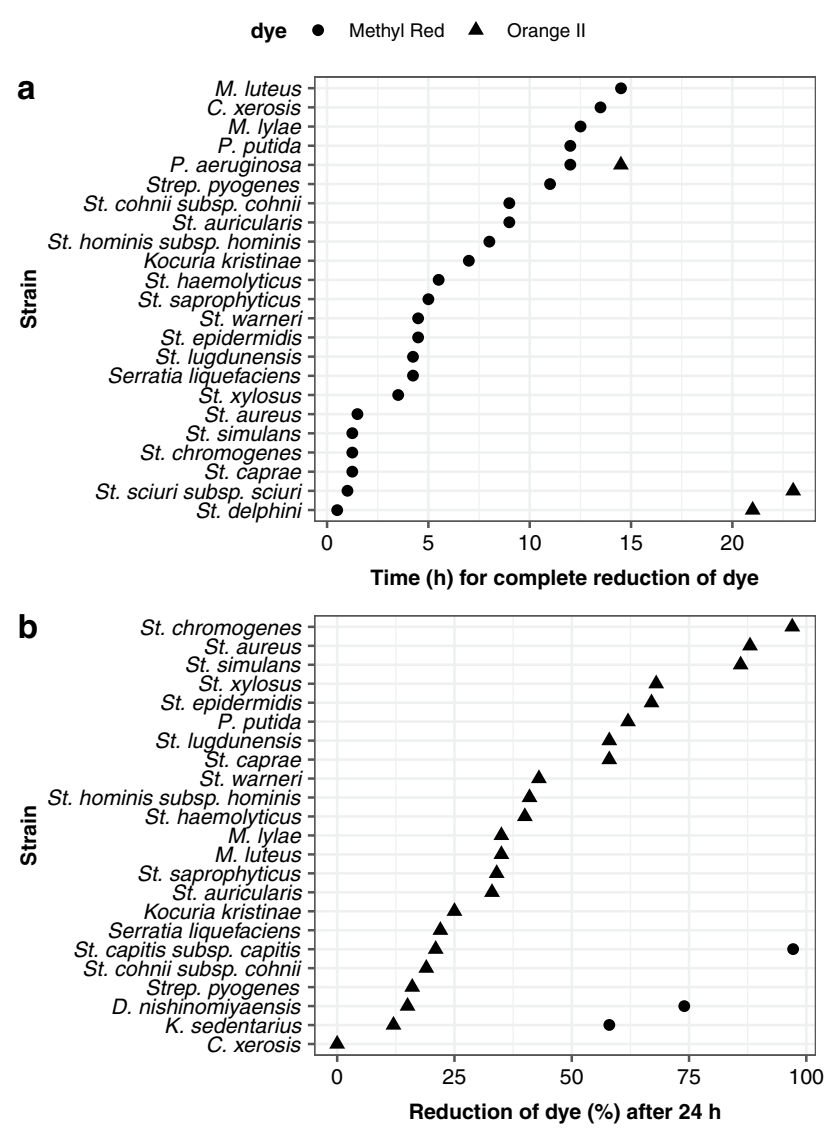

Fig. 8 Metabolic capacity of 26 different skin bacteria to reduce the azo dyes Methyl Red (MR) and Orange II (OrII). Each strain was incubated with $50 \mu \mathrm{M}$ MR or $100 \mu \mathrm{M}$ OrII at $37^{\circ} \mathrm{C}$ for $24 \mathrm{~h}$, except for $K$. sedentarius, which was incubated at $26{ }^{\circ} \mathrm{C}$ for $48 \mathrm{~h}$. The discoloration of the cell suspensions was monitored as a measure of azoreducing activity. a Strains showing complete dye reduction of MR or OrII over the required time. b Strains with incomplete dye reduction with the percentage of reduction at the end of the experiment. K. Kytococcus, D. Dermacoccus, C. Corynebacterium, Strep. Streptococcus, St. Staphylococcus, M. Micrococcus, P. Pseudomonas. Data from Stingley et al. (2010) (color figure online)

\section{Percutaneous absorption of aromatic amines and metabolism}

The skin penetration of pAAs, formed by reductive azo cleavage by the skin microbiome, and their subsequent metabolism are the next steps when looking on the exposure of the consumer towards textile azo dyes. The consideration of the cleavage products is important as many pAAs are suspected or known carcinogens (Chung 2015). Although being a very heterogeneous group of compounds with variant physiochemical properties, most pAAs are lipophilic and easily partition into the hydrophobic SC. Information on the dermal absorption of pAAs is generated in different regulatory areas for the risk assessment of cosmetic products (e.g., hair dyes, Platzek [2010]), industrial chemicals used as additives in mixtures and other products (Dennerlein et al. 2017; Korinth et al. 2007), pesticides (EFSA 2017) or pharmaceuticals (Lobo et al. 2014). It would be beyond the scope of this review to discuss all available data on the dermal absorption and metabolism of pAAs. The parameters influencing the dermal absorption of pAAs are e.g. discussed in Korinth et al. (2013) and the metabolism in Platzek (2010) and Brüning et al. (2009). Nevertheless, the look on some exemplary studies can provide an indication about the magnitude of pAA penetration. Experiments by Hotchkiss et al. (1993), Kenyon et al. (2004), Lürsen et al. (2006), Wellner et al. (2008), and Dennerlein et al. (2017) with dermal loads of pAAs in the dimension of the observed dye migration (maximum $0.0-11.9 \mu \mathrm{g} / \mathrm{cm}^{2}$ ) revealed a maximum percutaneous flux in the range from nearly zero (amount under the detection limit) up to $1.04 \mu \mathrm{g} / \mathrm{cm}^{2} / \mathrm{h}$ (Table S1, Supplementary material). Depending on the compound itself as well as the experimental setup and conditions, the maximum percutaneous flux of pAAs was up to 10-times higher than that observed for dyes under realistic starting concentrations. Even though the realistic starting concentration of the pAAs and the penetrated amount will probably be lower having regard to the reductive azo cleavage, it is essential to include the dermal penetration of pAAs when assessing the health risks resulting from the dermal exposure of consumers towards textile azo dyes.

\section{Conclusion}

The migration of (azo) dyes from clothing textiles to the skin, the dye absorption and reductive azo cleavage as well as the absorption of pAAs are important steps when calculating the exposure of consumers towards chemicals from textiles.

Migration values are influenced by many parameters and therefore refer to a defined dye-fabric system. Nevertheless, the studies discussed here showed maximum migration values of $0.5-1 \%$ of the dye load (maximum $0.83 \mu \mathrm{g}$ / $\mathrm{cm}^{2}$, ETAD (1983)) for new, unwashed textiles, which were dyed using state-of-the-art technology. These can be used as default values if data are missing. However, higher migration rates cannot be excluded for textiles with a bad color fastness for which maximum migrations of up to $11.9 \mu \mathrm{g} / \mathrm{cm}^{2}(5.4 \%)$ were observed (Platzek and Lang 2002). The reported dermal absorption of textile dyes varies widely across the studies, depending on experimental setup and dye properties. While many experiments showed no absorption through human skin, the maximum percutaneous flux of $0.2 \mu \mathrm{g} / \mathrm{cm}^{2} / \mathrm{h}$ was found with a surfactant substance as solvent and a high surface dose of $200 \mu \mathrm{g} / \mathrm{cm}^{2}$ (ETAD 1994). The maximum flux through human skin with sweat solution and a realistic applied dose $\left(4.2 \mu \mathrm{g} / \mathrm{cm}^{2}\right)$ was $0.09 \mu \mathrm{g} / \mathrm{cm}^{2} / \mathrm{h}$ (ETAD 1995). 
Many bacterial strains from the skin microbiome are able to reductively cleave azo dyes. Based on the little data available cleavage could theoretically take on any value between 0 and $100 \%$. From the studies discussed here and from waste water treatment, it is known that only a fraction of the available azo dye is cleaved. Because more recent data are missing, the value from Collier et al. (1993) of $~ 30 \%$ is hence used, although it is likely that azo cleavage was catalyzed by skininherent enzymes and not by skin bacteria. Further studies are therefore urgently needed to reduce uncertainties about the reductive azo cleavage by the skin microbiome. Values for the dermal absorption of pAAs vary widely in literature. Looking at exemplary experiments with starting concentrations in a realistic range, the maximum percutaneous flux ranges from nearly zero up to $1.04 \mu \mathrm{g} / \mathrm{cm}^{2} / \mathrm{h}$. This should be taken into account when assessing potential health risks of consumers from dermal exposure towards textile azo dyes.

In summary, the studies discussed here address various aspects of the dermal exposure of consumers towards dyes from clothing textiles that can form a basis for exposure assessment. However, the database for the migration, reduction and absorption of (azo) dyes and pAAs needs to be expanded using standardized and comparable experiments. In addition, missing toxicological reference values should be generated. This would enable a better risk assessment and ultimately provide a better protection of consumers.

Funding Open Access funding enabled and organized by Projekt DEAL.

\section{Compliance with ethical standards}

Conflict of interest The authors affirm that there are no conflicts of interest associated with this academic publication.

Open Access This article is licensed under a Creative Commons Attribution 4.0 International License, which permits use, sharing, adaptation, distribution and reproduction in any medium or format, as long as you give appropriate credit to the original author(s) and the source, provide a link to the Creative Commons licence, and indicate if changes were made. The images or other third party material in this article are included in the article's Creative Commons licence, unless indicated otherwise in a credit line to the material. If material is not included in the article's Creative Commons licence and your intended use is not permitted by statutory regulation or exceeds the permitted use, you will need to obtain permission directly from the copyright holder. To view a copy of this licence, visit http://creativecommons.org/licenses/by/4.0/.

\section{References}

Aldrich FD, Busby WF Jr, Fox JG (1986) Excretion of radioactivity from rats and rabbits following cutaneous application of two 14C-labeled azo dyes. J Toxicol Environ Health 18:347-355. https ://doi.org/10.1080/15287398609530876
Balszuweit F (2005) Freisetzung primärer aromatischer Amine aus Azofarbstoffen durch mikrobielle Spaltung, quantitative, parametrische und kinetische Aspekte. Dissertation, Freie Universität Berlin

Bechthold T, Pham T (2019) Textile Chemistry. De Gruyter, Berlin/ Boston

BfR (2012) Introduction to the problems surrounding garment textiles. German Federal Institute for Risk Assessment, Berlin

Brüning T, Käfferlein HU, Slowicki A (2009) Azofarbmittel und deren Hautgängigkeit beim Menschen. BGFA-Report 2. Editor: BGFA Forschungsinstitut für Arbeitsmedizin der Deutschen Gesetzlichen Unfallversicherung, Institut der Ruhr-Universität Bochum

Brüschweiler BJ, Merlot C (2017) Azo dyes in clothing textiles can be cleaved into a series of mutagenic aromatic amines which are not regulated yet. Regul Toxicol Pharmacol 88:214-226. https://doi. org/10.1016/j.yrtph.2017.06.012

Brüschweiler BJ, Kung S, Burgi D, Muralt L, Nyfeler E (2014) Identification of non-regulated aromatic amines of toxicological concern which can be cleaved from azo dyes used in clothing textiles. Regul Toxicol Pharmacol 69:263-272. https://doi. org/10.1016/j.yrtph.2014.04.011

Carliell-Marquet C, Barclay SJ, Naidoo N (1995) Microbial decolourisation of a reactive azo dye under anaerobic conditions. Water SA 21:61-69

Chengalroyen MD, Dabbs ER (2013) The microbial degradation of azo dyes: minireview. World J Microbiol Biotechnol 29:389399. https://doi.org/10.1007/s11274-012-1198-8

Chung KT (2015) Occurrence, uses, and carcinogenicity of arylamines. Front Biosci (Elite edition) 7:322-345

Ciba Spezialitätenchemie AG (2000) Bioavailability of disperse dyes, step: migration of disperse dyes from textiles into perspiration solution (not publically available)

Collier SW, Storm JE, Bronaugh RL (1993) Reduction of azo dyes during in vitro percutaneous absorption. Toxicol Appl Pharmacol 118:73-79. https://doi.org/10.1006/taap.1993.1011

Dennerlein K, Goen T, Zobel M, Boos AM, Drexler H, Kilo S (2017) Dermal penetration and resorption of beta-naphthylamine and $\mathrm{N}$-phenyl-beta-naphthylamine from lubricants in an ex vivo human skin model. Chemosphere 185:934-941. https://doi. org/10.1016/j.chemosphere.2017.07.070

ECHA (2016) Guidance on information requirements and chemical safety assessment. Chapter R.15: Consumer exposure assessment Version 3.0. https://echa.europa.eu/documents/10162 /13632/information_requirements_r15_en.pdf

ECHA (2019) Proposal: Restriction on the placing on the market of textile, leather, hide and fur articles containing skin sensitising substances. https://echa.europa.eu/de/registry-of-restrictio n-intentions/-/dislist/details/0b0236e182446136

EFSA (2017) Guidance on dermal absorption. EFSA J 15(6). https ://doi.org/10.2903/j.efsa.2017.4873

ETAD (1983) Final report on extractability of dyestuffs from textiles, project A 4007 (not publically available)

ETAD (1994) In vitro absorption of six disperse dyes through human and pig epidermis, project T2030: Part 1 (not publically available)

ETAD (1995) In vitro absorption of two disperse dyes from synthetic perspiration and five formulations, project T2030: Part 2 (not publically available)

ETAD (1997) Extractability of dyestuffs from textiles over a normal life time of use, project G 1033 (not publically available)

ETAD (2001) In vitro absorption of two disperse dyes through human and pig epidermal membranes (not publically available)

Feng J, Cerniglia CE, Chen H (2012) Toxicological significance of azo dye metabolism by human intestinal microbiota. Front Biosci (Elite edition) 4:568-586. https://doi.org/10.2741/400 
Friedlipartner AG (2009) Textilfarbstoffe: Inventar, Stoffdaten und Priorisierung verwendeter Substanzen

Hawkyard CJ, Kelly M (2000) A new approach to the assessment of standard depth. Color Technol 116:339-344. https://doi. org/10.1111/j.1478-4408.2000.tb00010.x

Heine E, Thomas H, Müller BM, Höcker H (1996) Entwicklung praxisgerechter Modelle für die Exposition mit chemischen Stoffen aus Textilien, Deutsches Wollforschungsinstitut (DWI) an der Technischen Hochschule Aachen. DWI Reports Volume 118 (not publically avaiable)

Heine E, Heinemann M, Thomas H, Höcker H (2000) Freisetzung von Textilhilfsmitteln und farbstoffen aus textilen Bedarfsgegenständen und Übergang auf die Haut, Abschlussbericht, Deutschen Wollforschungsinstituts (DWI) an der Technischen Hochschule Aachen (not publically available)

Hotchkiss SA, Hewitt P, Caldwell J (1993) Percutaneous absorption of 4,4'-methylene-bis(2-chloroaniline) and 4,4'-methylenedianiline through rat and human skin in vitro. Toxicol in Vitro $7: 141-148$

IARC (2010) IARC Monographs on the evaluation of carcinogenic risks to humans-some aromatic amines, organic dyes, and related exposures, vol 99. World Health Organization, International Agency for Research on Cancer, Lyon

ISO 105-E04 (1989) Textiles-tests for colour fastness-part E04: colour fastness to perspiration

Ito T, Shimada Y, Suto T (2018) Potential use of bacteria collected from human hands for textile dye decolorization. Water Resour Ind 20:46-53. https://doi.org/10.1016/j.wri.2018.09.001

Kahlberg Consulting (2019) Migration data of disperse dyes on PES substrates. https://echa.europa.eu/de/registry-of-restriction-inten tions/-/dislist/details/0b0236e182446136

Kenyon SH, Bhattacharyya J, Benson CJ, Carmichael PL (2004) Percutaneous penetration and genotoxicity of 4,4'-methylenedianiline through rat and human skin in vitro. Toxicology 196:65-75. https ://doi.org/10.1016/j.tox.2003.11.004

Korinth G, Weiss T, Penkert S, Schaller KH, Angerer J, Drexler H (2007) Percutaneous absorption of aromatic amines in rubber industry workers: impact of impaired skin and skin barrier creams. Occup Environ Med 64:366-372. https://doi.org/10.1136/ oem.2006.027755

Korinth G, Schaller KH, Drexler H (2013) Percutaneous absorption of aromatic amines and the risk assessment resulting from the dermal pathway. Front Biosci (Elite edition) 5:928-938

Krätke R, Platzek T (2004) Migrationsverfahren und Modelle zur Abschätzung einer möglichen Exposition mit Textilhilfsmitteln und -farbmitteln aus Bekleidungstextilien unter Anwendungsbedingungen. Empfehlung des Bundesinstituts für Risikobewertung:810-813

Levine WG (1991) Metabolism of azo dyes: implication for detoxication and activation. Drug Metab Rev 23:253-309. https://doi. org/10.3109/03602539109029761

LGC (1998) The risk of cancer caused by textiles and leather goods coloured with azo dyes-final report. A study for European Commission Directorate-General III
Lobo S, Li H, Farhan N, Yan G (2014) Evaluation of diclofenac prodrugs for enhancing transdermal delivery. Drug Dev Ind Pharm 40:425-432. https://doi.org/10.3109/03639045.2013.767828

Luersen L, Wellner T, Koch HM, Angerer J, Drexler H, Korinth G (2006) Penetration of beta-naphthylamine and o-toluidine through human skin in vitro. Arch Toxicol 80:644-646. https://doi. org/10.1007/s00204-006-0095-Z

Malinauskiene L, Zimerson E, Bruze M, Ryberg K, Isaksson M (2012) Patch testing with the textile dyes Disperse Orange 1 and Disperse Yellow 3 and some of their potential metabolites, and simultaneous reactions to para-amino compounds. Contact Dermat 67:130 140. https://doi.org/10.1111/j.1600-0536.2012.02080.x

Meinke M, Abdollahnia M, Gahr F, Platzek T, Sterry W, Lademann J (2009) Migration and penetration of a fluorescent textile dye into the skin - in vivo versus in vitro methods. Exp Dermatol 18:789-792. https://doi.org/10.1111/j.1600-0625.2009.00885.x

OECD (2005) OECD trade policy studies: environmental requirements and market access. OECD. https://doi.org/10.1787/9789264013 742 -en

Platzek T (2010) Risk from exposure to arylamines from consumer products and hair dyes. Front Biosci (Elite edition) 2:1169-1183

Platzek T, Lang C (2002) Freisetzung aromatischer Amine aus Azofarbstoffen in Textilien durch Hautbakterien. Bundesinstitut für gesundheitlichen Verbraucherschutz und Veterinärmedizin, Berlin

Platzek T, Lang C, Grohmann G, Gi US, Baltes W (1999) Formation of a carcinogenic aromatic amine from an azo dye by human skin bacteria in vitro. Hum Exp Toxicol 18:552-559. https://doi. org/10.1191/096032799678845061

Saratale RG, Saratale GD, Chang JS, Govindwar SP (2011) Bacterial decolorization and degradation of azo dyes: a review. J Taiwan Inst Chem Eng 42:138-157. https://doi.org/10.1016/j.jtice .2010.06.006

SCCS (2010) Basic criteria for the in vitro assessment of dermal absorption of cosmetic ingredients. Scientific Committee on Consumer Safety, Brussels

Solís M, Solís A, Pérez HI, Manjarrez N, Flores M (2012) Microbial decolouration of azo dyes: a review. Process Biochem 47:17231748. https://doi.org/10.1016/j.procbio.2012.08.014

Stingley RL, Zou W, Heinze TM, Chen H, Cerniglia CE (2010) Metabolism of azo dyes by human skin microbiota. J Med Microbiol 59:108-114. https://doi.org/10.1099/jmm.0.012617-0

Stolz A (2001) Basic and applied aspects in the microbial degradation of azo dyes. Appl Microbiol Biotechnol 56:69-80

Wellner T, Luersen L, Schaller KH, Angerer J, Drexler H, Korinth G (2008) Percutaneous absorption of aromatic amines-a contribution for human health risk assessment. Food Chem Toxicol 46:1960-1968. https://doi.org/10.1016/j.fct.2008.01.036

Publisher's Note Springer Nature remains neutral with regard to jurisdictional claims in published maps and institutional affiliations. 